\title{
Re-inspiring compassionate caring: the reawakening purpose workshop
}

\author{
Robin Youngson
}

\begin{abstract}
How best to strengthen compassion in healthcare has become a controversial subject, especially when governments attempt to 'implement' compassion through policy and regulation. This case study describes a workshop, designed according to principles of appreciative inquiry, which elicits stories of deep connection and caring, and uncovers the hidden strengths of the workshop participants. This re-connection to purposes generates positive energy and motivates people to strengthen their own caring and compassion. Participants are reminded of the values, hopes and aspirations that brought them into healthcare. Experience with this 'Reawakening Purpose' workshop in the UK, the USA, Australia and New Zealand shows it to be a transformative process for health professionals, even for those suffering from stress or burnout. It can be completed in 60 to 90 minutes and so is easily fitted into the working day. This workshop is a key process for inducting followers into an international social movement for compassionate, human-centred healthcare: 'Hearts in Healthcare'. It's argued that this grassroots approach to strengthening compassion may be much more effective than any top-down policy or regulation.
\end{abstract}

Keywords: Workshop, Appreciative inquiry, Story-telling, Strengths, Purpose, Social movement

\section{Background}

The government in the UK has made the implementation' of compassion a matter of national policy. All NHS staff have been told they must "embrace" the values of patient care set out in the national nursing strategy for England. Known as the " $6 \mathrm{Cs}$ ", the values are care, compassion, competence, communication, courage and commitment. Is a top-down approach to compassion the best strategy or can we better encourage compassionate caring at the grass-roots level? [this passage moved from conclusion].

'Hearts in Healthcare' is a global social movement for compassionate, human-centred healthcare. It's an informal network of health professionals, complementary and alternative therapists, students, patient advocates, health leaders and many others [1]. In a healthcare system beset with stress and burnout, the founders of the movement sought a process to liberate positive energy and reminded participants of the values, hopes and aspirations that brought them into healthcare. The 'Reawakening Purpose' workshop [2] is an effective process for reconnecting

Correspondence: robin@heartsinhealthcare.com

Hearts in Healthcare, PO Box 63, Raglan 3265, New Zealand health workers to the heart of their practice and strengthening caring and compassion.

The workshop was gradually developed after we were inspired by the results of using appreciative inquiry to explore questions of compassion and caring. When a group of health professionals is confronted with a challenge, their habitual thinking style quickly leads to a focus on problems, risks, lack of resources, and a tendency to blame others. Appreciative Inquiry [3] does exactly the opposite; it asks the question, "When did things work exceptionally well? Tell me a story". The process typically involves putting participants in pairs to interview each other, then sharing the stories with the bigger group. The facilitator then asks, 'What were the conditions that allowed this great teamwork or effective working? How can we create more of these conditions?' Although the use of appreciative inquiry in healthcare is very limited, it's a promising approach for bringing diverse groups of professionals together to improve patient care. The Center for Appreciative Practice in Virginia has published an inspiring book detailing their experience [3]. 


\section{Case presentation}

The twelve charge nurse managers from a busy NHS hospital in Wales shuffled into the workshop showing every sign of fatigue, stress and demoralization. Nobody made eye contact. The body language spoke of resentment and a wish to be elsewhere: attending to the thousand-andone demands of a near-impossible job. This is the stark reality of many of our hospitals, beset with overwork, stress and no time to care. How do we even begin the conversation about compassionate caring?

Ninety minutes later, the participants noisily left the room brimming with positive energy, enthusiasm, hope, and many practical ideas for improving the quality of compassionate caring on their wards. The startled Director of Nursing declared that her nurse managers had all had a "personality transplant". What process led to this transformation?

This event was not unique. The 'Reawakening Purpose' workshop has inspired participants in the UK, the USA, Australia and New Zealand. It appears to works with any mixture of health workers who have direct patient contact, including receptionists and office managers, and even a mixture of professionals and patients. Some attendees describe it as life-changing. A movie file is attached, giving an example of the kind of deeply moving stories elicited by the workshop [Additional file 1].

\section{The workshop process}

The Reawakening Purpose workshop pairs participants and asks them to interview each other. The question is, "Tell me a story of one day you had an extraordinary connection with a patient". The pairs swap roles at halftime then the whole group is reconvened in a circle. The facilitator remarks that the emotional process of sharing stories mirrors a daily challenge of clinical practice: how to end one emotionally charged patient encounter and then be fully present to the next patient. It's suggested that being aware of breathing is a helpful technique and the facilitator leads the group in three synchronized deep breaths. This helps the participants become still and attentive and it role-models the quality of presence desired in patient encounters.

Attendees are then invited to share their story again this time with the whole circle. A 'talking object' is used with a rule that only the person holding the object is permitted to speak. The group sits in silence until the first person picks up the object, tells their story, then places the object in the middle of the circle to wait for the next story-teller. Usually about three-quarters of the participants decide to share their story.

In every workshop we have heard profound and moving stories of compassionate caring. Many of the participants share tears. Two types of story regularly emerge: incidents from early in careers when the young health professionals were more open-hearted; and determined acts of rule-breaking to meet the deeper needs of a suffering patient.

Two nurses told us about a ventilated ICU patient who hadn't seen daylight for three weeks. Borrowing a portable ventilator and infusion pumps, these two nurses pushed the ventilated patient down the corridors and into the garden to enjoy the sunshine. Another courageous nurse described undoing the chains and shackles of an incarcerated AIDS patient who had been imprisoned for fear of spreading the disease. A doctor described how a hug with a patient changed his practice forever.

The process of sharing stories is spell-binding. When all have finished, the facilitator draws out lessons from the stories:

- Noting the way participants demonstrated skills in empathetic listening and examples of the observed body-language, such as mirrored gestures and posture.

- Commenting on the experience of having someone listen deeply, without interruption, and how meaningful and healing is that experience.

- Recognising the skills and strengths of the participants revealed in their stories - this has a remarkable impact on the way professionals perceive their colleagues.

- Highlighting the many examples of compassionate practices that can easily be woven into the busiest day.

- Reflecting how powerful it is to re-connect to the personal values and ideals that originally motivated a career in healthcare.

The workshop ends by asking each participant to name one simple compassionate practice they will use in the next day of patient care, or else teach to another. The entire workshop can be completed in 60 to $90 \mathrm{mi}$ nutes, depending on the number of participants.

\section{Discussion}

In a healthcare system beset with stress, cynicism and burnout it's difficult to initiate conversations about caring and compassion and the potential for intimate connections between health professionals and patients. Furthermore, the spiritual aspects of healthcare, and the feelings and vulnerabilities of health professionals are taboo subjects. Yet our international experience of 'Reawakening Purpose' shows these deep conversations can be easily achieved even with groups of very diverse experience and background.

It's a process that allows young graduates to share meaning and purpose with senior clinicians, either in a mixed group representing the care team, or a single professional group. It builds the bond between diverse participants, of all ages, and strengthens teamwork. The 
workshop is also suitable for non-clinical staff at the front line of care, such as receptionists and others with direct patient contact. In our latest workshop, we even had patient representatives tell moving stories of extraordinary connection to health professionals. The process has worked equally well in diverse cultural settings, from private healthcare providers in the USA to governmentfunded healthcare in the UK and NZ.

In our online community we hear many stories from health professionals who have recovered from burnout by reconnect to deeper purpose and adopting daily habits of kindness, compassion, appreciation and gratitude [4]. The Reawakening Purpose workshop inspires practitioners to adopt these practices.

This workshop has become so foundational, at Hearts in Healthcare we no longer contemplate any other process for a first engagement with a group or institution. In New Zealand, it will be incorporated in a Hearts in Healthcare national roadshow and campaign to strengthen compassionate caring in the NZ healthcare system. This campaign is a grassroots social movement, not a government-led strategy.

The workshop is subtly designed using the principles of positive psychology and appreciative inquiry. For that reason, we believe that anyone with a modicum of experience in small group teaching could successfully facilitate the process. Members of Hearts in Healthcare have free access to a comprehensive workshop kitset including a facilitators' manual, introductory slides, a stepby-step video guide to the workshop process, key point handouts, and a bibliography of supporting evidence.

This case study has limitations. Our report is merely observational, from twenty instances of facilitating the workshop. We would welcome research to assess the attitudes and beliefs of workshop participants and whether the workshop has any lasting impact on health professionals' practice.

\section{Conclusion}

Our experience suggests that the best strategy to achieve compassionate caring is not a top-down series of directives and regulations but rather a grass-roots approach using appreciative inquiry to bring out the very best in health workers and to re-energise their hopes, ideals and aspirations. This is an untested hypothesis we put forward to stimulate further research and experimentation.

\section{Additional file}

Additional file 1: "Gauri's Story".

Competing interests

The Hearts in Healthcare movement is funded by the author, Robin Youngson, and his wife Meredith Youngson. It's supported by a social enterprise including consulting work, lectures, workshops and book publishing. The Reawakening Purpose workshop as described is one of the activities offered in the consulting business.

\section{Author information}

Robin Youngson is an anaesthetist trained in the UK but working in New Zealand. As Acting Chair of the national EpiQual Committee and subsequently a founding member of the Quality Improvement Committee, he advised the NZ government on strategies eventually leading to legislation in 2010, which established the New Zealand Health Quality and Safety Commission. He was also the NZ representative on the World Health Organization International Steering Committee for Patient Safety Solutions. In 2011, having quit all leadership roles, Robin resigned his public hospital job to devote all his time and passion to the Hearts in Healthcare movement. He's a Fellow of the International Centre for Compassionate Organizations.

\section{Acknowledgements}

Thanks to Hansa Natola for filming "Gauri's Story" (the attached file).

Received: 28 March 2014 Accepted: 27 June 2014

Published online: 27 October 2014

\section{References}

1. Hearts in Healthcare. http://heartsinhealthcare.com

2. Reawakening Purpose Workshop. http://heartsinhealthcare.com/workshop/ reawakening-purpose/.

3. May N, Becker D, Frankel R, Haizlip J, Harmon R, Plews-Ogan M, Schorling J Williams A, Whitney D: Appreciative Inquiry in Healthcare: Positive Questions to Bring out the Best. Brunswick, Ohio: Crown Custom Publishing; 2011.

4. Youngson R: Time to Care: How to Love your Patients and your Job. Raglan, New Zealand: Rebelheart Publishers; 2012

\section{doi:10.1186/s40639-014-0001-0}

Cite this article as: Youngson: Re-inspiring compassionate caring:

the reawakening purpose workshop. Journal of Compassionate Health Care 2014 1:1

\section{Submit your next manuscript to BioMed Central and take full advantage of:}

- Convenient online submission

- Thorough peer review

- No space constraints or color figure charges

- Immediate publication on acceptance

- Inclusion in PubMed, CAS, Scopus and Google Scholar

- Research which is freely available for redistribution 